\title{
Desconstruindo expectativas de gênero a partir de uma posição minoritária: como dialogar com homens autores de violência contra mulheres?
}

\author{
Deconstructing gender expectations from a minority standpoint: \\ how to enter into a dialogue with male perpetrators of violence \\ against women?
}

Jan Billand ${ }^{1}$

Vera Silvia Facciolla Paiva ${ }^{1}$

${ }^{1}$ Departamento de

Medicina Preventiva,

Faculdade de Medicina,

Universidade de São Paulo.

Av. Prof Mello Moares 1721,

Cidade Universitária. 05508-

900 São Paulo SP Brasil.

jbilland@yahoo.fr

\begin{abstract}
This article discusses limits and possibilities of the practice of a reflection group together with male perpetrators of violence against women. It is based on an ethnographic study, which included participant observation and interviews with the facilitators of a group held in a feminist non-governmental organization in partnership with the criminal justice system. Starting with the discussion of an emblematic scene, we argue in favor of this dialogue process as an alternative that could expand the limits of the judiciary approach. In order to enter into a dialogue with the peer group, the facilitators must consider the minority position of feminist viewpoints in the field of masculinity. This step alone makes it possible to cooperate with the participants such that, as they spontaneously and genuinely share their experiences, they come to acknowledge the inadequacy of their expectations regarding women. This way, a dynamic of care takes place between men, which is conducive to the mitigation of violence and serves as a complement to the promotion of gender equality.
\end{abstract}

Key words Men, Masculinity, Violence against women, Professional practice, Group processes
Resumo Este artigo discute limites e possibilidades da prática de um grupo reflexivo junto a homens autores de violência contra mulheres. Apoia-se em um estudo etnográfico que incluiu observação-participante e entrevistas com os facilitadores de um grupo realizado em uma organização feminista não governamental em parceria com a justiça criminal. A partir da discussão de uma cena emblemática, argumentamos a favor de um processo de trabalho dialógico como uma alternativa que pode expandir os limites da abordagem judicial: para dialogar com o grupo de pares, os facilitadores precisam levar em consideração a posição minoritária dos pontos de vista feministas no campo das masculinidades. Só esse passo permite cooperar com os participantes para que, a partir do compartilhamento espontâneo e genuino de experiências, reconheçam o caráter inadequado de suas expectativas em relação às mulheres. Deste modo instaura-se uma dinâmica de cuidado entre homens, favorável à mitigação das violências e complementar da promoção da equidade de gênero.

Palavras-chave Homens, Masculinidade, Violência contra a mulher, Prática profissional, Processos Grupais 


\section{Introdução}

A violência contra mulheres vem sendo tratada como uma questão de saúde há cerca de duas décadas. Para sua prevenção, a Organização Mundial da Saúde tem incentivado o trabalho junto a homens ${ }^{1}$. Diversas publicações internacionais de impacto no campo da saúde trataram desse tipo de intervenção, mais recentemente em busca de uma compreensão renovada da sua lógica ${ }^{2-5}$. Discutem sobretudo intervenções preventivas que focalizam os determinantes culturais da violência contra mulheres, e raramente a intimidade das práticas de intervenção junto aos homens que a perpetraram. Um relatório da OMS de $2003^{6}$ menciona que a maioria desses programas se desenvolve em associação entre o sistema carcerário e as organizações não governamentais. Trabalhadores da saúde mental envolvidos na área também tendem a seguir uma lógica de controle social própria da justiça ${ }^{7,8}$ : abordam apenas homens condenados ou denunciados, construindo, assim, uma minoria definida como desviante e distinta da população masculina geral ${ }^{9}$. A concepção dominante na literatura nacional e internacional que fundamenta as práticas de intervenção - caracterizando principalmente intervenções de base chamada feminista, psico-educativa e cognitivo-comportamental"11 - é o foco na "responsabilização” dos homens pela violência cometida.

No Brasil, programas públicos que abordam especificamente homens autores de violência contra mulheres não são do campo da saúde, e sim da segurança pública: Delegacias da Mulher, Juizados de Violência Doméstica e Familiar contra a Mulher e os recém-criados Serviços de Responsabilização e Educação do Agressor ${ }^{10}$ (antigos "centros de educação e reabilitação para os autores de violência" e outros programas de "recuperação e reeducação" previstos pela Lei Maria da Penha $\left.{ }^{11}\right)$. Há limitações e efeitos colaterais dessas intervenções baseadas no poder judiciário.

O foco na responsabilização pela violência cometida, assim como a concepção da educação que caracteriza esses serviços judiciários ${ }^{7,8,12,13}$, procuram forçar a adequação dos indivíduos abordados a um discurso hegemônico que não é, por sua vez, problematizado ${ }^{9,14}$. Para adequar indivíduos, usam-se técnicas tais como: confrontar suas justificativas e racionalizações quando minimizam sua responsabilidade pela violência, ensinar-lhes táticas de negociação menos violentas, ensiná-los a expressar empatia e vulnerabilidade, ou ainda ensinar-lhes princípios de direitos humanos das mulheres ${ }^{12,15,16}$. Por trás de todos esses procedimentos encontram-se os mesmos pressupostos: os participantes aceitarão o diagnóstico dos técnicos a respeito deles, e aderirão ao tratamento e receita de comportamento prescrito.

Mesmo os profissionais que realizam semelhantes intervenções costumam reconhecer que "não há, muitas vezes, o interesse por parte dos homens em mudar"15. A maioria dos homens autores de violência contra mulheres não se responsabiliza por seus atos espontaneamente ${ }^{17}$, resiste aos esforços dos facilitadores para levá-los a expressar empatia e fragilidades ${ }^{16}$, e não adere a intervenções que exigem que assumam outros discursos ${ }^{18}$. Altas taxas de abandono sustentam os resultados artificialmente positivos dessas intervenções: muitas vezes, apenas os participantes que cumprem o "tratamento" prescrito são avaliados, usando os homens que desistem como grupo controle ${ }^{19}$, como se esses abandonos não fossem também resultados da intervenção; ou ainda, avalia-se o efeito das intervenções em função da "dose" de tratamento recebida ${ }^{20}$, o que permite novamente desconsiderar o abandono enquanto resultado negativo. $\mathrm{O}$ mesmo acontece quando muitas intervenções descritas na literatura selecionam ativamente uma minoria de participantes já motivados. Por exemplo, realiza-se "um acordo, em que, para participar do grupo, daquele dia em diante, [o homem] não cometeria mais violência contra a mulher"21; ou ainda, exige-se o pagamento de uma taxa para atestar o seu compromisso com a mudança ${ }^{15}$. Em todos esses casos, coloca-se como pré-requisito um resultado que se deveria almejar.

Há ainda outros modelos de intervenção que usam medidas coercivas para obter a adesão dos participantes: em troca de uma redução de pena, ou ameaçando-os através de relatórios sobre seu desempenho destinados aos juízes, ou ainda, humilhando aqueles que não respondem de acordo com as expectativas dos técnicos ${ }^{7,16}$. Entretanto, até os técnicos desconfiam dos resultados assim produzidos ${ }^{9,12}$. Observam que os participantes tendem a modificar apenas o seu discurso, adaptando-o às expectativas dos facilitadores, mas sem alterar o modo como se relacionam com suas parceiras ${ }^{16}$, tal como na cena seguinte relatada por um especialista inglês:

Alguns anos atrás eu avaliei um programa de tratamento para abusadores sexuais. Além de administrar testes psicométricos, eu visitei o domicílio de todos os homens que tinham completado o programa. Os dados psicométricos relativos a James (pseudônimo) eram positivos; eles indicavam que suas atitudes (a respeito da responsabilidade 
por seus abusos, do dano causado à vítima, e sua atitude com mulheres) tinham mudado de modo significante. Eu perguntei a James se o programa o tinha mudado de algum modo. Ele disse que tinha mudado sim. Antes do programa ele era um 'PCM' (porco chauvinista macho), mas suas atitudes tinham mudado. Enquanto ele me dizia isso, ele interrompia repetidamente a nossa conversa para mandar sua esposa me fazer chá, passar suas roupas e obter dinheiro para o programa da noite que eles queriam fazer depois que eu saísse. Isto me apresentou um problema para interpretar os dados: os questionários psicométricos e a resposta de James à minha pergunta indicavam que o tratamento tinha tido um efeito desejável, mas seu comportamento com a esposa o contradizia ${ }^{9}$.

A cena evidencia que os homens podem mudar seu discurso, atitudes e representações (inclusive de si mesmo), sem alterar as relações de poder que estabelecem com suas parceiras. Um homem pode não usar violência contra uma mulher também porque consegue controlá-la sem violência, ou sem violência denunciada. Numa hipótese pessimista, diversos autores sugerem que, em vez de representar um progresso rumo à equidade de gênero, a diminuição da violência observada no processo de algumas intervenções indicaria apenas que os homens conseguem evitar denúncias ${ }^{16,19}$, ou ainda, que aprimoraram seu controle sobre as mulheres, inclusive usando as técnicas de negociação e habilidades discursivas ensinadas no âmbito dos programas ${ }^{16}$; alguns autores também sugerem que os homens estariam reproduzindo contra suas parceiras as técnicas de poder e controle exercidas contra eles no âmbito da intervenção ${ }^{7,9}$. Como evitar essa convergência perversa entre os objetivos dos técnicos (mitigar a violência contra as mulheres) e dos participantes (controlar as mulheres sem serem denunciados)?

\section{Reflexões desde o campo da saúde}

Entre os autores que refletem sobre os princípios do Sistema Único de Saúde (SUS), J. R. Ayres $^{22}$ recomenda que os profissionais "orientem a busca de êxito técnico de suas intervenções na direção apontada pelos projetos de felicidade dos destinatários de sua ação": a condição para o que o autor chama de sucesso prático. Porém, no caso de uma intervenção junto a homens autores de violência contra mulheres, a busca de tal sucesso prático parece mais problemática, na medida em que os projetos de felicidade desses homens parecem inicialmente incompatíveis com os das mulheres, ou ainda, inaceitáveis na perspectiva feminista que fundamenta o horizonte ético-político da Lei Maria da Penha ${ }^{10}$.

Abrindo mão do sucesso prático, muitas intervenções descritas na literatura aparentam-se àquilo que L. B. Schraiber ${ }^{23}$ descreve como a "realização do exclusivo ponto de vista do profissional que, de algum modo, 'convenceu' ao outro de sua razão científica e tecnológica, lembrando que este convencer raramente é se colocar em acordo dialógico com o outro". Vimos que nessas intervenções, monológicas ${ }^{9}$, os projetos de felicidade dos homens ainda resistem e ressurgem na forma de danos colaterais e consequências indesejadas ${ }^{7,24}$.

Deve-se, portanto, intensificar a repressão? Procuramos, pelo contrário, compreender a possibilidade de uma intervenção junto a homens autores de violência contra mulheres que não abra mão do diálogo, em acordo com os fundamentos éticos das práticas em saúde.

\section{Método}

Fundamentaremos o argumento central do texto usando uma cena ${ }^{25}$ observada no processo de uma pesquisa de Doutorado ainda não publicada. O estudo, etnográfico ${ }^{26,27}$, buscou compreender limites e possibilidades de um processo de trabalho intitulado "grupo reflexivo para homens autores de violência contra mulheres". O estudo articulou observação participante, entrevistas com os "facilitadores" e uma análise documental.

O grupo estudado é realizado voluntariamente por três homens - profissionais de nível universitário, acadêmicos e ativistas - desde a "facilitação" das reuniões até a gestão administrativa. Foram inspirados, entre outros, por sua participação em projetos pioneiros junto a homens heterossexuais na resposta brasileira à aids, em que a saúde do homem, as relações de gênero e a violência entre parceiros sempre foram desafios. O grupo acontece na cidade de São Paulo em um coletivo feminista que é bastante reconhecido no campo do enfrentamento à violência contra as mulheres. Sem conseguir ser incluído em alguma política pública, o trabalho se beneficia, desde 2009, de acordos realizados diretamente com Juizados Criminais da Violência contra a Mulher. Os juízes oferecem a homens autuados pela Lei Maria da Penha a oportunidade de participar de 16 reuniões do grupo, como cumprimento antecipado de uma "medida socioeducativa". As reuniões, de duas horas, acontecem semanalmente sob a orientação de um ou dois facilitadores. $\mathrm{O}$ grupo é exclusivamente masculino e não aceita a 
presença de mulheres como facilitadoras ou convidadas.

A cena narrada abaixo descreve o relato de um participante do grupo e a reação de um dos pesquisadores, presente como observador-participante. Para torná-la mais inteligível para o leitor, restituiremos os aspectos observáveis por todos os atores presentes no cenário, assim como as reflexões que ocorreram ao pesquisador durante a cena que presenciou, inseridas na narração a seguir, representando o que chamamos de cenas internas ${ }^{25}$ : um diálogo reflexivo cujo cenário é a "cabeça", o mundo dos pensamentos do pesquisador - que é homem, branco, estrangeiro, psicólogo e se considera pró-feminista. Para ressaltar o caráter subjetivo desta narrativa, mantivemos o uso da primeira pessoa.

\section{A cena: como dialogar com Danilo?}

O coletivo feminista que acolhe as reuniões do grupo reflexivo, funciona no que já foi uma casa residencial. Os homens se reúnem em um salão dessa casa, uma vez por semana, no fim da tarde, durante um horário reservado, de modo que nenhuma mulher esteja presente no local. A sala é inteiramente ocupada por uma roda de cadeiras, a não ser em um dos cantos no qual se encontra uma televisão e um leitor de videocassetes.

Naquele dia, o grupo acolheu três novos participantes: entre eles, Danilo (nome fictício). Branco, de olhos azuis, ele aparenta ter quarenta anos. Sob a solicitação do facilitador, ele se apresenta: dentista de profissão; pai de dois filhos jovens; ainda casado com a mãe deles, embora no processo de separação, por causa da denúncia de violência que ela realizou contra ele. $\mathrm{O}$ facilitador pede para que ele fale um pouco do que aconteceu. Danilo insiste que não cometeu nenhum dos atos pelos quais está sendo autuado. $\mathrm{O}$ facilitador lhe responde que, mesmo assim, algo deve ter acontecido para que ele se encontre ali presente. Danilo começa então a explicar que, na família da sua esposa, as pessoas são sujeitas à "depressão”. Aliás, quando nasceu o primeiro filho do casal, sua esposa sofreu uma "depressão pós-parto": naquela época, ela queria entregar a criança para a adoção. Porém, continua Danilo, graças ao "tratamento" psiquiátrico assim como o "apoio" da família, ela "acabou aceitando o filho”.

Essa colocação de Danilo me leva a suspeitar que esteja tentando deslegitimar as falas e os atos de sua esposa, atribuindo-lhe uma frágil saúde mental. Eu já havia identificado o mesmo procedimento em outros relatos de participantes.
Lembro-me que, de acordo com diversas autoras feministas ${ }^{28,29}$, acusar uma mulher de irracionalidade é um modo clássico de silenciar e controlá-la (uma prática chamada gaslighting), e que as mulheres em situação de violência acabam sendo mais frequentemente afetadas por transtornos mentais $^{30,31}$. Eu passo então a considerar como uma forma de violência o tratamento recebido pela esposa de Danilo: ela tinha verbalizado seu desejo de não ser mãe, mas não foi ouvida, e acabou sendo coagida pela "família", com auxílio psiquiátrico. Todo este raciocínio constitui uma cena interna, uma repercussão da cena sobre a minha subjetividade, como parte da observação participante.

Danilo continua seu relato. Depois deste episódio, novos motivos de conflito surgiram entre os cônjuges. A esposa "não trabalhava", todavia gostava muito de viagens, sobretudo para a Europa, e usava os recursos do seu marido a serviço da sua paixão para viajar. Danilo conta que até tentou ajudá-la a montar sua própria agência de viagens, para que ela pudesse trabalhar naquilo que lhe interessava. Contudo, em pouco tempo a empresa faliu, pois a esposa gastava os fundos para financiar suas próprias viagens em vez de procurar clientes. Para completar a descrição dos modos de sua esposa, Danilo ainda relata para o grupo outro episódio, no qual ela gastou, para seu uso pessoal, o dinheiro que era destinado a pagar a mensalidade da escola do filho. No entanto, em vez de se arrepender, a esposa costumava afirmar, "na cara" de Danilo, que considerava seu casamento como uma "faixada", pois além do dinheiro, ele "não servia para nada".

O relato de Danilo comove o resto do grupo. No entanto, eu não compartilho desta emoção, pois interpreto os atos da esposa como formas de resistência contra a maternidade compulsória ${ }^{32}$. Eu entro então na conversa para perguntar para Danilo o que aconteceu, afinal, para a esposa processá-lo. Danilo explica que ela era bacharel em Direito, e usou os seus estudos para procurar uma maneira de se separar dele com a maior compensação financeira possível. De acordo com Danilo, recorreu à ajuda de amigos para montar uma falsa acusação de violência doméstica contra ele.

Eu pergunto então a Danilo por que, na medida em que ele já conhecia a intenção da esposa de processá-lo, ele não procurou se separar dela antes que fosse tarde demais. Danilo, exaltado, responde que ficou por causa das crianças: "ser pai" sempre foi seu desejo, e ser acolhido, ao voltar do trabalho, pelos gritos de "papai querido", e receber os abraços carinhosos dos seus dois fi- 
lhos, é “a maior felicidade da [sua] vida”. No entanto, sua esposa já tinha lhe dito algumas vezes, ainda que fosse para "provocá-lo", que planejava "encontrar outro pai para as crianças".

Danilo diz ter aprendido em algum lugar que se uma criança crescer junto com um homem até os cinco anos de idade, ela passará a chamá-lo de "pai" pelo resto de sua vida. Por isso, na espera da filha mais jovem ultrapassar os fatídicos cinco anos, Danilo tolerava as despesas, "provocações" e ameaças de sua esposa. No caso de um divórcio, ele sabia que dificilmente conseguiria obter a guarda das crianças. Então Danilo explica que, para suportar os anos restantes, ele recorria à fé. Quando sua esposa "vinha para cima" dele para "provocá-lo", ele ficava quieto e pensava: “é Satanás usando essa pessoa inocente para me testar; rezava então mentalmente, pedindo ajuda a Jesus para "não ouvir" os dizeres da sua esposa. Danilo conclui esta parte da sua narração evocando a profunda "desilusão" que sua experiência lhe causou, por divergir de modo tão radical e inesperado de como ele compreende que um casamento deveria ser: uma "sinergia", "igual àquela que une dois sócios” numa empresa bem-sucedida.

Para os outros participantes, Danilo se torna admirável por sua insistência em querer ser pai apesar da adversidade. No entanto, eu reparo que Danilo, quando fala da paternidade, não menciona nenhuma vez alguma preocupação pelo bem -estar das crianças. Parece unicamente preocupado por sua própria felicidade, diferentemente das mulheres que dizem se preocupar pelas necessidades dos filhos quando lhes é perguntado o motivo que as impede de se separar de homens violentos $^{33,34}$.

Isso me faz pensar que a esposa de Danilo foi "utilizada" por ele como um mero recurso instrumental para realizar seu "sonho de ser pai". A "sinergia" evocada por Danilo me parece mais um processo assimétrico, no qual o homem deseja e a mulher se adequa. Por isso, quando ela afirma interessar-se apenas pelo dinheiro do seu marido, eu entendo que ela estaria reagindo em espelho ao modo como ela é tratada: ele a utiliza para ter filhos, e ela para ter dinheiro. Esta interpretação, somada ao modo como Danilo diz se recusar a ouvir a esposa, assim como o apoio recebido do grupo, me deixa indignado.

Tentando compartilhar essa indignação, declaro para Danilo que acho estranho o fato dele valorizar a "sinergia" no casal, embora ele mesmo faça de tudo para não ouvir a esposa e trate as queixas dela como "provocações" sem sentido. Acrescento que o esforço de Danilo para manter seu casamento, apesar do desejo da esposa de se separar dele, me parece uma forma de "egoísmo", sobretudo se considerar o modo como ele mesmo definiu o sentido de "ser pai", apenas em relação a cuidados "recebidos" por parte dos filhos, sem nem mencionar cuidados que ele ofereceria para eles.

Danilo mantém uma atitude digna e responde na forma de uma pergunta: "Você é pai?" Como eu respondo que não, ele conclui: "Se você fosse pai, você entenderia”. A partir deste momento, permaneço quieto e ranzinza, convencido de que não conseguirei comunicar o meu ponto de vista e que, portanto, não tenho mais motivos para participar da conversa. Aparentemente considerando o episódio encerrado, o resto do grupo retoma a conversa sem integrar nenhuma das minhas críticas. Em vez disso, com o apoio do facilitador, diversos participantes compartilham suas próprias histórias com Danilo, a fim de mostrar para ele que foram confrontados a problemas semelhantes aos seus.

\section{Primeira reflexão: como intervir a partir de uma posição social minoritária?}

Esta cena ilustra um conflito entre dois pontos de vista morais divergentes acerca de um mesmo relato. Danilo e o resto do grupo condenam moralmente a esposa de Danilo por não ser uma "boa mãe" nem uma "boa esposa”, e não percebem nenhum problema no fato de de Danilo impor à sua esposa o seu próprio "sonho de ser pai”. Isso é percebido como uma incoerência pelo pesquisador que, apoiado em leituras feministas, compreende o "egoísmo" da esposa como uma reação legítima ao "egoísmo" de Danilo.

O fracasso do diálogo nesta cena converge com outras observações e experiências no campo: os participantes, assim como muitos homens na sociedade, resistem com êxito à compreensão do ponto de vista moral de mulheres que não se comportam de acordo com as expectativas de um homem ${ }^{17,18}$. A cena ilustra a legitimidade sociocultural desta resistência - sustentada até pelo discurso psiquiátrico que, historicamente, patologizou as mulheres que não se adequavam ao seu papel de gênero.

O fracasso do pesquisador no âmbito da cena remete à sua falta de compreensão deste contexto social em que se insere. A posição que o pesquisador defende não é só minoritária no contexto do grupo; mas também ao nível social. Seu discurso não possui legitimidade na ótica dos seus interlocutores e seria reconhecido apenas em âmbitos 
feministas ou de debate sobre direitos da mulher. Portanto, o pesquisador se equivoca ao agir frente ao grupo como se representasse alguma autoridade moral. Isso fica claro quando Danilo aponta que não pode julgar sua experiência pois não "é pai”. Por contraste, com maior sucesso prático, o facilitador não procurou, neste estágio da intervenção, se contrapor às normas morais vigentes entre os participantes; apesar de não ser pai, conseguiu assim participar da conversa ulterior, sem ser questionado.

Como o pesquisador nesta cena, muitas intervenções pretendem confrontar as bases dos raciocínios morais dos homens, qualificando-os de "distorções cognitivas" sem compreender que se tratam de práticas culturalmente enraizadas e socialmente legitimadas. Como aponta Cowburn ${ }^{9}$ o máximo que se pode obter nessas circunstâncias é a criação de "jogos de linguagem” diferentes, mas que só podem ser "jogados" no contexto da intervenção - fora deste contexto, ficariam incompreendidos por seus pares, como aconteceu com o pesquisador na cena. Cowburn recomenda "trabalhar com (e dentro) dos jogos de linguagem masculinos" culturalmente vigentes. Os técnicos precisam trabalhar a partir de uma posição social paritária e, ao mesmo tempo, minoritária.

Essa abordagem contrasta com o exercício do poder típico das intervenções vinculadas ao judiciário, que dispensa habitualmente os seus agentes de dialogar com as pessoas cujas vidas estão encarregados de administrar, tratando-se de pregar o esperado "bom comportamento" sem considerar sua adequação no contexto psicossocial.

Por um lado, a Lei Maria da Penha não poderia ser aplicada sem alguma ruptura de diálogo. Por outro lado, o modo como essa lei rompe com as normas culturais vigentes faz com que a maioria dos participantes, como Danilo, não compreenda o motivo da sua autuação, pois considera ter agido dentro de padrões morais socialmente valorizados para homens ${ }^{35,36}$ (defendendo seus "direitos" de pai e de provedor da família).

O que significa, na prática, intervir desde uma posição social minoritária, e quais resultados podem ser alcançados desta maneira? Discutiremos, a seguir, as possibilidades apresentadas pelo desempenho dos facilitadores da intervenção estudada.

\section{Segunda reflexão: compartilhar experiências leva os homens a desconstruir representações da "boa feminilidade" e favorece atitudes de cuidado}

A primeira atuação dos facilitadores, consonante com sua posição minoritária, sempre é incentivar os homens a compartilhar seus relatos com seus pares. Os homens que se encontram nestas atividades de grupo pertencem a todas as camadas sociais, exercem todo tipo de profissão, e têm todo tipo de cor de pele. Seus modos de se relacionar com a masculinidade também apresentam certa diversidade. Entretanto, todos compartilham situações nas quais ficaram insatisfeitos pelo desempenho de uma mulher, e parecem considerar como legítima uma possível reação violenta nessas situações. Por exemplo, Danilo falou da "desilusão" que lhe inspirava sua experiência conjugal. Os outros participantes reconheceram em Danilo certo ideal do "bom marido" (branco, boa profissão, dedicado à paternidade, recorrendo à fé para evitar o recurso à violência física). Por isso seu relato deixou os seus pares indignados pelo modo como sua esposa rompeu com representações da "boa" feminilidade, impedindo-o de alcançar os seus objetivos em relação à vida conjugal e à paternidade. A cena ilustra que não é suficiente ser aquele "bom marido" para ter a certeza de obter o desempenho "naturalmente complementar" requisitado de uma mulher.

Apesar disso, Danilo ainda parece considerar que sua esposa deveria ter colaborado com seu projeto familiar. Ele não ouvia o que sua esposa tinha a dizer quando não condizia com este projeto. Em outra ocasião, um participante, que também encenava um modelo dominante de masculinidade - e era jovem, branco, ex-estudante de teatro, trabalhador - afirmou sua própria incompreensão nos seguintes termos: "Me digam se eu sou louco, porque eu fiz tudo certo, e no final deu tudo errado". O grupo compartilha indignação e desamparo frente àquilo que lhes parece uma incompreensível agressividade das mulheres contra eles. Como poderíamos então conduzir Danilo e seus pares a não reproduzir o mesmo padrão de relacionamento com outras mulheres?

Graças ao trabalho dos "facilitadores", cujas intervenções incentivam o compartilhamento dos relatos, e sua discussão entre pares, os participantes ouvem relatos convergentes, de homens com histórias e perfis diversos. Muitos são com- 
partilhados pela primeira vez e todos reconhecem que é excepcional ouvir homens maduros expondo para seus pares suas experiências fracassadas e doloridas em relação a mulheres. Com o tempo, a repetição dos relatos leva os participantes a parar de considerar suas experiências conjugais e familiares como anomalias ou consequências de certa falta de "sorte com as mulheres": passam a reconhecer sua normalidade, no sentido estatístico do termo. Eles ampliam sua consciência sobre o caráter irrealista das suas expectativas em relação às mulheres, enquanto categoria supostamente uniforme de seres humanos cuja vocação seria atender e responder às necessidades deles.

Muitas mulheres se beneficiaram recentemente de ganhos de poder na sociedade, potencializados pela Lei Maria da Penha, assim como pelo aumento da presença das mulheres no mercado do trabalho, pelo reconhecimento mais frequente dos seus direitos em caso de divórcio, etc. Os homens acolhidos no grupo são confrontados aos efeitos dessa mudança sobre seus próprios projetos de vida. Eles percebem que essas mulheres têm o poder de se opor a seus desejos e decisões, e até de prejudicá-los.

Essa ampliação de consciência ${ }^{25}$ proporciona uma reação emocional que um dos facilitadores chama de "crise". Isso não significa que os participantes manifestem remorso ou empatia pelas ex -parceiras - eles ainda se recusam a compreender os atos dessas mulheres na sua perspectiva, e continuam justificando seus próprios atos, mesmo quando os consideram como "erros". Entretanto, passam a desconfiar das mulheres e dos scripts culturais do amor romântico e da harmonia familiar. Começam a incentivar-se reciprocamente a "ficar ligeiro", a reagir rapidamente e "cair fora" em casos de conflitos íntimos, ou ainda, "se precaver" contra as imprevisíveis "traições" das parceiras. Alertados pelos pares e seus relatos repetidos de experiências infelizes, rompem mais cedo os ciclos de violência ${ }^{37,38}$, pois acham suspeitas as reconciliações inesperadas, e ficam mais preocupados pelos conflitos pendentes nos seus próprios relacionamentos. Em síntese, embora ainda atribuam às parceiras a responsabilidade moral pelos conflitos e suas consequências, a desconstrução do ideal da "boa feminilidade" leva os participantes a atribuir-se a responsabilidade prática de não permanecer em situações onde poderiam ser tentados de recorrer à violência.

Assim, o reconhecimento compartilhado pelos homens de suas experiências infelizes em relação às mulheres favorece a instauração de re- lações de cuidado e autocuidado entre eles: além de dissuadir seus pares da ideia de se reconciliar com as mulheres que os denunciaram, os homens começam a aconselhar-se a desistir de qualquer ideia de vingança, percebendo que eles também iriam se prejudicar com isso, já sendo autuados. Deste modo, o processo de trabalho consegue prevenir violências que os homens poderiam cometer em reação à ruptura do relacionamento e à sua autuação.

Após essa "crise", percebendo que os ganhos de poder das mulheres na sociedade podem constituir uma causa comum por trás das suas desventuras individuais, os participantes manifestam mais curiosidade para análises sociais e históricas das relações de gênero trazidas pelos facilitadores. No entanto, o grupo só se apropria dessas análises na medida em que os saberes teóricos e acadêmicos vêm complementar e consolidar os saberes práticos oriundos dos relatos de experiências pessoais, em vez de pretender desqualificar e substituí-los: isto significa que os facilitadores mantêm a posição minoritária que ocupam no grupo. No âmbito da cena, o pesquisador não respeitou este limite e condição da prática e suas colocações não foram integradas na conversa.

É preciso ressaltar a interdependência entre este tipo de intervenção junto a homens e outras realizadas junto às mulheres. Sem intervenções sociais paralelas para dar às mulheres os recursos necessários para romper com as expectativas dos homens e impor seus próprios projetos de felicidade, pode-se supor que eles não compartilhariam o que Danilo chamou de "desilusão" e não encontrariam motivos para repensar seus padrões de relacionamento. Assim, o sucesso da intervenção estudada é indissociável do seu contexto e do cenário marcado pela Lei Maria da Penha, entre outras políticas que favorecem ganhos de poder para as mulheres.

Reciprocamente, sem o tipo de conversa em grupo facilitada pela intervenção estudada, os ganhos de poder alcançados pelas mulheres e seus impactos na vida dos homens não seriam suficientes para provocar a chamada "crise". Na ausência de um compartilhamento das suas "desilusões”, frustrações, sentimentos de injustiça, de incompreensão ou de desamparo, os homens persistem nas suas expectativas. Acreditando serem casos isolados, podem inclusive recorrer a estratégias mais violentas na esperança de obter das mulheres o desempenho requisitado ou para reafirmar seu status frente aos pares ${ }^{38}$. 


\section{Considerações finais}

Compreendemos que o processo de trabalho deste "grupo reflexivo para homens autores de violência contra mulheres" alcança uma forma de sucesso prático ${ }^{23}$; foi possível compreendê-lo por contraste com a cena do diálogo fracassado entre Danilo e o observador-participante. As implicações são de duas ordens. Primeiramente, identificamos uma possibilidade de trabalhar de modo dialógico junto a homens autores de violência contra mulheres, em vez de compreender a promoção da equidade de gênero como "realização do exclusivo ponto de vista do profissional"24 como é frequente na literatura. Ou seja, a produtividade do trabalho com este público a partir de uma posição minoritária deve ser reconhecida pelos técnicos que querem trabalhar junto a homens numa perspectiva feminista de promoção da equidade de gênero. Um discurso pró-feminista não lhes confere autoridade moral no cenário atual das masculinidades: por isso precisam renunciar à simples defesa do ponto de vista moral de mulheres quando estas se opõem às expectativas dos homens, e desenvolver outros caminhos dialógicos.

A segunda implicação diz respeito à desconstrução das expectativas de gênero com ou entre homens. A representação social da "boa feminilidade" baseada nos projetos de felicidade masculinos serve de base para a reprodução de relações de cuidado violentas e desiguais ${ }^{39,40}$. A intervenção estudada leva os participantes a uma reflexão crítica sobre suas expectativas em relação às mulheres, partindo de suas próprias experiências compartilhadas. Isso possibilita a interrupção e a prevenção da violência contra mulheres e também representa alguns passos na promoção da equidade de gênero.

Considerando que "a transgressão das normas de gênero e o fracasso em cumprir as expetativas de boa feminilidade e de masculinidade bem-sucedida estão entre os mais importantes disparadores de violência entre parceiros íntimos" ${ }^{41}$, observamos que discutir, primeiro, as expectativas de boa feminilidade constitui uma possível porta de entrada para, em um segundo momento, discutir as expectativas dos homens em relação à masculinidade bem-sucedida. Os projetos de felicidade masculinos costumam ser frustrados pelas resistências das mulheres em colaborar, e isso produz violência. Facilitar um questionamento coletivo desses projetos - o que os facilitadores chamam de produzir uma crise é mais interessante que tentar impor aos homens projetos alternativos, pensados sem a sua participação e a partir de pontos de vista femininos/ feministas que eles não reconhecem como moralmente legítimos.

Outros tipos de intervenção junto a homens, mesmo não ligados à justiça nem à prevenção da violência contra mulheres, podem se beneficiar desta perspectiva. No âmbito das práticas em saúde, a dificuldade de levar os homens a cuidarem de si e dos outros é frequentemente observada ${ }^{39,40,42,43}$. Os estudos em saúde atribuem geralmente o problema a representações culturais da masculinidade incompatíveis com as práticas de cuidado, conotadas como femininas. Entretanto, nossas observações sugerem que as representações da feminilidade também podem constituir um obstáculo para a promoção de práticas de cuidado junto a homens: para que cuidar de si e dos outros se as mulheres parecem "naturalmente" mais competentes para isso? Neste cenário, uma desconstrução das expectativas dos homens a respeito das mulheres pode ser um preâmbulo necessário.

Enfim, nossas observações enraizam-se no contexto de uma articulação particular entre a intervenção junto a homens e intervenções junto a mulheres. Os resultados sugerem que é necessário dialogar com os homens (ou melhor, entre homens), para que ampliem sua consciência acerca do desencontro entre suas experiências pessoais e as expectativas que orientam suas relações com mulheres - ou ainda, precisamos criar espaços de socialização onde homens possam refletir sobre o fracasso dos seus projetos de felicidade (patriarcais), frustrados pelos ganhos de poder das mulheres. Porém, este processo reflexivo só pode ocorrer na medida em que outras intervenções sociais, almejando as mulheres, já estiverem promovendo esses ganhos de poder. $\mathrm{O}$ trabalho junto aos homens não garante, por si só, avanços rumo à equidade de gênero; entretanto, faz-se necessário para prevenir reações violentas deles frente a avanços já empreendidos pelas mulheres $^{1,4,44}$. 


\section{Colaboradores}

J Billand trabalhou na pesquisa, na metodologia, na concepção, e na redação final. VSF Paiva trabalhou na metodologia e na redação final.

\section{Referências}

1. World Health Organization (WHO), London School of Hygiene and Tropical Medicine. Preventing intimate partner and sexual violence against women: taking action and generating evidence. Geneva: WHO; 2010.

2. Jewkes R, Flood M, Lang J. From work with men and boys to changes of social norms and reduction of inequities in gender relations: a conceptual shift in prevention of violence against women and girls. Lancet 2015; 385(9977):1580-1589.

3. Fleming PJ, Gruskin S, Rojo F, Dworkin SL. Men's violence against women and men are inter-related: Recommendations for simultaneous intervention. Soc Sci Med 2015; 146:249-256.

4. Flood M. Work with men to end violence against women: a critical stocktake. Cult Health Sex 2015; 17(Supl. 2):1-18.

5. Jewkes R, Morrell R, Hearn J, Lundqvist E, Blackbeard D, Lindegger G,. Hegemonic masculinity: combining theory and practice in gender interventions. Cult Health Sex 2015; 17(Supl. 2):96-111.

6. Rothman EF, Butchart A, Cerdá, M. Intervening with perpetrators of intimate partner violence: a global perspective. Geneva: World Health Organization; 2003.

7. Mankowski ES, Haaken J, Silvergleid CS. Collateral damage: An analysis of the achievements and unattended consequences of batterer interventions programs and discourse. J Fam Violence 2002; 17:167-184.

8. Augusta-Scott T. Reinventing the wheel: finding new stories for men who batter [dissertação]. Halifax: Dalhousie University; 1999.

9. Cowburn M. Constructive work with male sex offenders: male forms of life, language games and change. In: Gorman K, Gregory M, Hayles M, Parton N, editores. Constructive Work with Offenders. London: Jessica Kingsley; 2006. p. 159-176.

10. Brasil. Presidência da República. Secretaria de Políticas para as Mulheres. Rede de enfrentamento à violência contra mulheres. Brasília: Assessoria de Comunicação da Secretaria de Políticas para as Mulheres; 2011.

11. Lima DC, Büchele F. Revisão crítica sobre o atendimento a homens autores de violência doméstica e familiar contra as mulheres. Physis 2011; 21(2):721-743.

12. Brown M. "We are neutral therapists": Psychology, the state and social control. Aust Psychol 2002; 37:165-171.

13. Beiras A, Moraes M, Alencar-Rodrigues R, Cantera LM. Políticas e leis sobre violência de gênero - reflexões críticas. Psicol Soc 2012; 24(1):36-45.

14. Cowburn M. Hegemony and discourse: reconstruing the male sex offender and sexual coercion by men. Sex Evol Gend 2005; 7(3):215-231.

15. Toneli MJF, Lago MCS, Beiras A, Climaco DA. Atendimento a homens autores de violência contra as mulheres: experiências latino-americanas. Florianópolis: UFSC/ CFH/NUPPE; 2010.

16. Schrock DP, Padavic I. Negotiating Hegemonic Masculinity in a Batterer Intervention Program. Gend Soc 2007; 21(5):625-649.

17. Moraes AF, Ribeiro L. As políticas de combate à violência contra a mulher no Brasil e a 'responsabilização' dos 'homens autores de violência'. Sex Salud Soc - Rev Latinoam 2012; 11:37-58. 
18. Catlett BS, Toews ML, Walilko V. Men's gendered constructions of intimate partner violence as predictors of court-mandated batterer treatment drop out. Am J Community Psychol 2010; 45(1-2):107-123.

19. Feder L, Wilson DB. A meta-analytic review of court-mandated batterer intervention programs: Can courts affect abusers' behavior? J Exp Criminol 2005; 1(2):239-262.

20. Gondolf EW. Evaluating batterer counseling programs: A difficult task showing some effects and implications. Agression and Violent Behavior 2004; 9(6):605-631.

21. Urra F. Masculinidades: a construção social da masculinidade e o exercício da violência. In: Blay EA, organizador. Feminismos e masculinidades. Novos caminhos para enfrentar a violência contra a mulher. São Paulo: Cultura Acadêmica; 2014. p. 117-137.

22. Ayres JRCM. Uma concepção hermenêutica de saúde. Physis 2007; 17(1):43-62.

23. Schraiber LB. Quando o 'êxito técnico' se recobre de 'sucesso prático': o sujeito e os valores no agir profissional em saúde. Cien Saude Colet 2011; 16(7):3041-3042.

24. Augusta-Scott T. As if they were human: a different take on perpetrator accountability. 2010. [acessado 2016 maio 8]. Disponível em: http://www.transformativejustice.eu/wp-content/uploads/2010/02/augusta-scottcomp-zine-imposed.pdf

25. Paiva V. Cenas da vida cotidiana: metodologia para compreender e reduzir a vulnerabilidade na perspectiva dos direitos humanos. In: Paiva V, Ayres JRCM, Buchalla CM, organizadores. Vulnerabilidade e direitos humanos - Prevenção e promoção da saúde - Livro I - Da doença à cidadania. São Paulo: Juruá Editora, 2012. p. 165-208.

26. Favret-Saada J. Les mots, la mort, les sorts. Paris: Gallimard; 1977.

27. Tedlock B. Ethnography and Ethnographic Representation. In: Denzin NK, Lincoln YS, editors. Handbook of qualitative research. Thousand Oaks: Sage publications; 2000, p. 455-486.

28. Molinier P. Des différences dans les voix différentes: entre l'inexpressivité et la surexpressivité, trouver le ton. Rech Féministes 2015; 28(1):45-60.

29. Abramson K. Turning up the Lights on Gaslighting. Philos Perspect 2014; 28(1):1-30.

30. Ludermir AB, Schraiber LB, D’Oliveira AFPL, FrançaJunior I, Jansen HA. Violence against women by their intimate partner and common mental disorders. Soc Sci Med 1982 2008; 66(4):1008-1018.

31. Santos AMCC. Articular saúde mental e relações de gênero: dar voz aos sujeitos silenciados. Cien Saude Colet 2009; 14(4):1177-1182.

32. Bensusan H. Quem pode fugir dos filhos indesejados? Rev Estud Fem 2012; 20(1):322-324.

33. Instituto Brasileiro de Opinião Pública e Estatística (IBOPE), Instituto Avon. Percepções e reações da sociedade sobre a violência contra a mulher. São Paulo: IBOPE, Instituto Avon; 2009.
34. Zancan N, Wassermann V, Lima GQ. A violência doméstica a partir do discurso de mulheres agredidas. Pensando Fam 2013; 17(1):63-76.

35. Feriani DM. Entre pais e filhos: práticas judiciais nos crimes em família [tese]. Campinas: Universidade Estadual de Campinas; 2009.

36. Connell RW, Messerschmidt JW. Masculinidade hegemônica: repensando o conceito. Rev Estud Fem 2013; 21(1):241-282.

37. Walker LE. Battered women and learned helplessness. Victimology 1977; 2(3-4):525-534.

38. Vasselier-Novelli C, Heim C. Représentations du couple et de la famille, chez les auteurs de violences conjugales à partir d'expériences comparées de groupes de paroles. Thérapie Fam 2010; 4(31):397-415.

39. Spencer B. La femme sans sexualité et l'homme irresponsable. Actes Rech En Sci Soc 1999; 128(1):29-33.

40. Souza CСBX. Até que a morte os separe: os cônjuges cuidadores, profissionais de saúde e o cuidar [dissertação]. São Paulo: Universidade de São Paulo; 2013.

41. Abramsky T, Watts CH, Garcia-Moreno C, Devries K, Kiss L, Ellsberg M, Jansen HA, Heise L. What factors are associated with recent intimate partner violence? findings from the WHO multi-country study on women's health and domestic violence. BMC Public Health 2011; 11:17.

42. Gomes R, Moreira MCN, Nascimento EF, Rebello LEFS, Couto MT, Schraiber LB. Os homens não vêm! Ausência e/ou invisibilidade masculina na atenção primária. Cien Saude Colet 2011; 16(1):983-992.

43. Gomes R, Nascimento EF, Araújo FC. Por que os homens buscam menos os serviços de saúde do que as mulheres? As explicações de homens com baixa escolaridade e homens com ensino superior. Cad Saude Publica 2007; 23(3):565-574.

44. Kim JC, Watts CH, Hargreaves JR, Ndhlovu LX, Phetla G, Morison LA, Busza J, Porter JD, Pronyk P. Understanding the Impact of a Microfinance-Based Intervention on Women's Empowerment and the Reduction of Intimate Partner Violence in South Africa. Am J Public Health 2007; 97(10):1794-1802.

Artigo apresentado em 12/01/2016

Aprovado em 02/08/2016

Versão final apresentada em 04/08/2016 